\title{
Liberation Medicine: a Community Partnership and Health Advocacy Curriculum for Internal Medicine Residents
}

\author{
Erin Goss, $M D^{7} \oplus$, Shwetha lyer, $M D^{7}$, Julia Arnsten, $M D, M P H^{2}$, Linda Wang, $M D^{3}$, and \\ Clyde Lanford Smith, MD, MPH, DTM\&H
}

\begin{abstract}
'Division of General Internal Medicine, Department of Medicine, Albert Einstein College of Medicine/Montefiore Medical Center, Bronx, NY, USA; ${ }^{2}$ Division of General Internal Medicine, Department of Medicine, Albert Einstein College of Medicine/Montefiore Medical Center, Bronx, NY, USA; ${ }^{3}$ Division of General Internal Medicine, Department of Medicine, Icahn School of Medicine at Mount Sinai, New York, NY, USA; ${ }^{4}$ Department of Medicine, Brigham and Women's Hospital, Boston, MA, USA.
\end{abstract}

$\mathrm{J}$ Gen Intern Med 35(10):3102-4

DOI: $10.1007 / \mathrm{s} 11606-019-05518-1$

(c) Society of General Internal Medicine 2019

\section{INTRODUCTION}

Physicians and professional organizations endorse the value of community and legislative health advocacy, ${ }^{1}$ but community health advocacy training is often neglected in medical training. To address this, in 2000, we implemented a Liberation Medicine (LM) curriculum for Montefiore's Primary Care/Social Medicine (PC/SM) residents. Defined as the conscious, conscientious use of healthcare to promote social justice and human dignity, ${ }^{2}$ LM provides a framework to support community efforts to address social arrangements that disproportionately impact health and well-being among poor and marginalized persons. We describe the evolution of our LM curriculum from 2000 to 2017 and present preliminary evaluation results from 2016 to 2017.

\section{METHODS}

In 2015, we performed a rigorous exercise to enhance our existing LM curriculum. We invited third-year PC/SM residents who had completed the curriculum to a focus group, then used their feedback to create four curricular aims aligned with ACGME milestones for systems-based practice (Table 1): (1) define and contextualize LM, (2) promote community engagement, (3) foster mentoring relationships with faculty physician advocates, and (4) improve resident advocacy skills.

To achieve aim (1), we developed two sessions to introduce LM. To achieve aims (2) and (3), faculty physician advocates and/or leaders of community-based organizations (CBOs) lead/co-lead sessions on local community issues; these sessions also describe strategies for and challenges to successful

Received October 7, 2019

Accepted October 22, 2019

Published online November 25, 2019 partnerships, as well as for career development in community health advocacy. To achieve aim (4), we developed an advocacy writing series for residents to learn about written advocacy, draft and workshop social media posts, and submit advocacy writing to media outlets. Our revised LM curriculum was instituted in 2016.

To evaluate our revised LM curriculum, we developed a 20item pre/post survey to assess impact on residents' confidence in their health advocacy knowledge and skills. Survey items were grouped into four domains: ability to define LM, individual advocacy, community advocacy, and public health advocacy. Residents rated agreement with each item on a 6point Likert scale ( $1=$ strongly disagree, $6=$ strongly agree); survey completion was optional. Results were analyzed continuously using nonparametric paired $t$ tests. We also queried graduating PC/SM residents regarding involvement in health advocacy and community partnerships. Einstein's IRB approved the protocol.

\section{RESULTS}

Ten PC/SM residents completed the revised LM curriculum in both 2016 and 2017; surveys were administered to all 20 residents. Both pre- and post-curriculum surveys were completed by $17 / 20$ residents $(85 \%)$. We observed significant improvements in self-reported confidence in two domains: ability to define LM and public health advocacy (Table 2). Of 20 residents, three published op-eds, 16 used social media for health advocacy, nine participated in advocacy through professional organizations, and 12 collaborated with CBOs. Graduating residents reported that the curriculum supported their physician identity: "Liberation Medicine fought burnout. I didn't just [become a physician] to fill out prior authorizations." Some described challenges engaging in advocacy during residency, but hoped to later: "I can't keep up a commitment during residency. I think this [training] will be valuable in the future." "One of my goals for fellowship is to be more engaged with community partnerships." 
Table 1 Original (2000) and Current (2016-2018) Liberation Medicine Seminars, and Participating Community Partners

\begin{tabular}{|c|c|c|c|}
\hline Aim & Original seminars (2000) & Current seminars (2016-2018) & Community partners \\
\hline $\begin{array}{l}\text { Aim 1: To define and } \\
\text { contextualize LM }\end{array}$ & $\begin{array}{l}\text { Liberation Theology } \\
\text { Health and Human Rights }\end{array}$ & $\begin{array}{l}\text { Liberation Theology } \\
\text { Health and Human Rights }\end{array}$ & $\begin{array}{l}\text {-Doctors for Global Health } \\
\text {-Médecins Sans Frontières }\end{array}$ \\
\hline \multirow[t]{6}{*}{$\begin{array}{l}\text { Aim 2: To promote community } \\
\text { engagement }\end{array}$} & $\begin{array}{l}\text { Community-Oriented } \\
\text { Primary Care in El Salvador } \\
\text { and the Bronx }\end{array}$ & $\begin{array}{l}\text { Community-Oriented Primary Care } \\
\text { Theory and Practice }\end{array}$ & \\
\hline & $\begin{array}{l}\text { Societal Costs of Uninsured } \\
\text { in the U.S. }\end{array}$ & Prescription Drug Pricing & -Legal Aid Society \\
\hline & $\begin{array}{l}\text { Race, Gender, and } \\
\text { Immigration }\end{array}$ & Incarceration as a Health Determinant & $\begin{array}{l}\text {-Close Rikers Campaign } \\
\text {-Osborne Association (Re-entry organization }\end{array}$ \\
\hline & Oppression Medicine & Advocacy for People Who Use & for formerly incarcerated persons) \\
\hline & (Tuskegee Syphilis Study, & Drugs & -Drug Policy Alliance \\
\hline & Rwandan Genocide) & $\begin{array}{l}\text { Lesbian Gay Bisexual Transgender } \\
\text { Queer (LGBTQ) Health Advocacy } \\
\text { Housing and Health }\end{array}$ & $\begin{array}{l}\text {-Bronx Trans Working Group } \\
\text {-BxMpowerment } \\
\text {-Corporation for Supportive Housing }\end{array}$ \\
\hline \multirow{4}{*}{$\begin{array}{l}\text { Aim 3: To foster mentoring } \\
\text { relationships with physicians } \\
\text { engaged in health advocacy }\end{array}$} & Community-Oriented & Physician-Pharmaceutical Industry & -National Physicians Alliance \\
\hline & Primary Care in El Salvador & Relationships & \\
\hline & and the Bronx & Research-Based Health Activism & -Physicians for a National Health Program \\
\hline & The Art of Healing & $\begin{array}{l}\text { Racism in Medicine } \\
\text { Incarceration as a Health } \\
\text { Determinant } \\
\text { Advocacy for People Who Use } \\
\text { Drugs }\end{array}$ & -Montefiore’s Coalition Against Racism \\
\hline $\begin{array}{l}\text { Aim 4: To improve resident } \\
\text { advocacy skills }\end{array}$ & $\mathrm{n} / \mathrm{a}$ & $\begin{array}{l}\text { Writing for Advocacy } \\
\text { Faculty-Resident Writing } \\
\text { Workshops (2) }\end{array}$ & -Physicians for a National Health Program \\
\hline
\end{tabular}

Table 2 Results of Pre/Post Survey of Residents' Liberation Medicine Knowledge and Skills $(N=17)$

\begin{tabular}{|c|c|c|c|}
\hline & Pre-curriculum* & Post-curriculum & $P$ value \\
\hline \multicolumn{4}{|l|}{ Define Liberation Medicine } \\
\hline I can describe the concept of Liberation Medicine & $3.53 \pm 0.95$ & $5.00 \pm 0.69$ & $<0.0001$ \\
\hline I recognize how to apply the ideals of Liberation Medicine to my clinical practice & $3.17 \pm 0.99$ & $4.78 \pm 0.73$ & $<0.0001$ \\
\hline I can describe biological, psychological, and social factors that influence the & $5.17 \pm 0.79$ & $5.39 \pm 0.78$ & 0.36 \\
\hline \multicolumn{4}{|l|}{ health of individuals and families } \\
\hline I have an awareness of the impact of societal injustice on health status & $5.61 \pm 0.50$ & $5.50 \pm 0.79$ & 0.63 \\
\hline I am comfortable defining implicit bias & $4.61 \pm 0.92$ & $5.22 \pm 0.88$ & 0.04 \\
\hline \multicolumn{4}{|l|}{ Individual advocacy } \\
\hline I can address social determinants of health in clinical care with my patients & $4.78 \pm 1.00$ & $4.89 \pm 0.90$ & 0.7 \\
\hline My own subconscious bias has the potential to impact the medical care I deliver & $5.61 \pm 0.61$ & $5.22 \pm 0.65$ & 0.07 \\
\hline I am able to advocate for individual patients and families within clinical encounters & $4.78 \pm 0.65$ & $5.00 \pm 0.69$ & 0.3 \\
\hline I can promote human dignity and patient empowerment within the clinical encounter & $4.89 \pm 0.68$ & $5.00 \pm 0.91$ & 0.61 \\
\hline \multicolumn{4}{|l|}{ Community advocacy } \\
\hline $\begin{array}{l}\text { I can identify specific examples where communities or community organizations have } \\
\text { attempted to address social determinants of health }\end{array}$ & $4.72 \pm 1.07$ & $4.94 \pm 0.87$ & 0.26 \\
\hline I can promote principles of social medicine within the larger medical community & $4.94 \pm 0.94$ & $4.78 \pm 0.81$ & 0.53 \\
\hline I can identify strategies to collaborate with communities to address the & $3.94 \pm 1.06$ & $4.28 \pm 0.96$ & 0.16 \\
\hline \multicolumn{4}{|l|}{ health needs of that community } \\
\hline I am able to advocate for my patient population on a local level & $4.17 \pm 0.86$ & $4.44 \pm 0.78$ & 0.35 \\
\hline \multicolumn{4}{|l|}{ Public health advocacy } \\
\hline I recognize how to apply the ideals of Liberation Medicine to clinical research & $2.61 \pm 0.98$ & $4.67 \pm 0.77$ & $<0.0001$ \\
\hline I am able to advocate for my patient population at a national level & $3.53 \pm 1.04$ & $4.39 \pm 0.92$ & 0.009 \\
\hline I recognize the power of the physician's voice in the public domain & $4.94 \pm 0.80$ & $5.33 \pm 0.84$ & 0.17 \\
\hline I am comfortable communicating with my key legislators about issues & $3.39 \pm 1.42$ & $4.22 \pm 1.40$ & 0.005 \\
\hline \multicolumn{4}{|l|}{ that are important to my patients } \\
\hline I am comfortable writing an editorial about an issue important to my patients & $3.00 \pm 1.08$ & $4.33 \pm 0.91$ & $<0.0001$ \\
\hline I recognize how research results can be used as a tool for advocating & $5.00 \pm 0.91$ & $5.11 \pm 0.90$ & 0.61 \\
\hline \multicolumn{4}{|l|}{ on behalf of patients and communities } \\
\hline I am able to apply research results to advocate on behalf of patients and communities & $4.06 \pm 1.06$ & $4.89 \pm 1.08$ & 0.003 \\
\hline
\end{tabular}

*Rated on a Likert scale where $1=$ strongly disagree to $6=$ strongly agree 


\section{DISCUSSION}

Our preliminary results demonstrate that a community partnership and health advocacy curriculum enhances residents' confidence in health advocacy knowledge and skills. After curriculum completion, residents partnered with CBOs and used social media for health advocacy. Specific strengths of our LM curriculum include faculty physicians' role modeling community engagement, and practical experience with advocacy writing.

Our curriculum adds to a modest but growing literature on advocacy training during residency. Surveys of established physician advocates demonstrate that mentorship and training facilitate engagement in health advocacy, ${ }^{3}$ but few studies describe efforts to mentor residents to incorporate advocacy into their careers. Existing studies include descriptions of health policy and legislative advocacy training, ${ }^{4}$ and of a research-based health advocacy curriculum, ${ }^{5}$ but we found no descriptions of skills-based community health advocacy curricula for residents. Studies also report course satisfaction and perceived confidence, rather than skill development. ${ }^{6}$

Our preliminary evaluation utilized a pre/post survey of residents' confidence in their knowledge and skills, which is a limitation. Additionally, the strong mission of Montefiore's PC/SM program attracts residents who value community engagement and health advocacy; two-thirds of surveyed residents reported prior experience with advocacy. Further research is needed to replicate our results in other IM residency programs and to understand the impact of our curriculum on local community health.

Corresponding Author: Erin Goss, MD; Division of General Internal Medicine, Department of Medicine Albert Einstein College of Medicine/Montefiore Medical Center, Bronx, NY, USA (e-mail: egoss@montefiore.org).

Compliance with Ethical Standards: Einstein's IRB approved the protocol.

\section{REFERENCES}

1. Gruen, R.L., E.G. Campbell, and D. Blumenthal, Public roles of US physicians: community participation, political involvement, and collective advocacy. Jama, 2006. 296(20): p. 2467-75.

2. Liberation Medicine. Available at: https://www.dghonline.org/content/ liberation-medicine. Accessed February 15, 2018

3. Law, M., Leung, P., Veinot, P., Miller, D., and M. Mylopoulos, A Qualitative Study of the Experiences and Factors That Led Physicians to Be Lifelong Health Advocates. Acad Med, 2016. 91(10): p. 1392-1397.

4. Long, T., Chaiyachati, K. H., Khan, A., Siddharthan, T., Meyer, E., and R. Brienza, Expanding Health Policy and Advocacy Education for Graduate Trainees. J Grad Med Educ, 2014. 6(3): p. 547-50.

5. Basu, G., Pels, R. J., Stark, R. L., Jain, P., Bor, D. H., and D. McCormick, Training Internal Medicine Residents in Social Medicine and Research-Based Health Advocacy: A Novel, In-Depth Curriculum, Acad Med, 2017. 92(4): p. 515-520.

6. Catalanotti, J., Popiel, D., Johansson, P., and Z. Talib, A Pilot Curriculum to Integrate Community Health Into Internal Medicine Residency Training. J Grad Med Educ, 2013. 5(4): p. 674-7.

Publisher's Note Springer Nature remains neutral with regard to jurisdictional claims in published maps and institutional affiliations. 